\title{
Movimento Empresa Júnior e Pacto consultoria: conceitos, estrutura e legados
}

Recebido em 17.07.2014. Aprovado em 10.10.2014 Avaliado pelo sistema double blind review

\author{
Hugo Pessanha Souza \\ hpessanha@pactoconsultoriair.com \\ Universidade Federal Fluminense \\ Júlia Ferreira Gouveia \\ jgouveiapacto@gmail.com \\ Universidade Federal Fluminense \\ Natália Cantarino Féres \\ ncferespacto@gmail.com \\ Universidade Federal Fluminense
}

\begin{abstract}
Resumo
O Movimento Empresa Júnior é um movimento universitário que tem por propósito levar aos estudantes uma experiência laboratorial das práticas gerenciais. Abordaremos neste artigo o conceito de empresa júnior, as instâncias deste movimento, seu propósito e a história da Pacto Consultoria - a Empresa Júnior de Gestão de Negócios e Turismo da UFF.
\end{abstract}

Palavras-chaves: Empresa Júnior, federação, confederação, rede e Pacto Consultoria.

\section{Abstract}

The Junior Enterprise Movement is an university movement that aims to take to the students a laboratory experience of managment practices. We will discuss in the article the concept of a junior enterprise, the instances of this movement, it's purpose and the history of Pacto Consultoria - Empresa Júnior de Gestão de Negócios e Turismo da UFF.

Keywords: Junior Enterprise, federation, confederation, network and Pacto Consultoria.

\section{Introdução}

O Movimento Empresa Júnior é, hoje, o maior movimento de empreendedorismo universitário do mundo, presente em mais de 15 países e com mais de 22 mil jovens envolvidos na geração de negócios, segundo a JADE - European Confederation of Junior Enterprises.

O Movimento surgiu na França em 1967, com objetivo de ajudar a inserir jovens universitários no mercado de trabalho por meio da realização de serviços, como estudos de mercado e enquetes comerciais para empresas. Rapidamente a ideia se difundiu no meio acadêmico francês e, na década de 80 , o modelo consolidou-se e começou a se difundir internacionalmente. 
Em 1988 as ideias foram trazidas para o Brasil pela Câmera de Comércio e Indústria Franco Brasileira. As empresas juniores pioneiras no Brasil foram as da Escola Politécnica da Universidade de São Paulo (USP), da Fundação Getúlio Vargas e da Universidade Federal da Bahia.

O movimento chegou ao Rio de Janeiro em 1990 com a fundação da EJCM - a Empresa Júnior de Consultoria em Microinformática da UFRJ. Posteriormente, o movimento ganhou força também na Universidade Federal Fluminense no ano de 1995, com a fundação da Meta Consultoria - Empresa Júnior de Engenharia da UFF - e da Pacto Consultoria - Empresa Júnior de Gestão de Negócios da UFF.

Desde a sua fundação, o objetivo do movimento é capacitar seus membros para o mercado de trabalho. No Brasil, o movimento possui grande tendência ao empreendedorismo e trabalha com o propósito de transformar o Brasil em um país empreendedor buscando "Formar, por meio da vivência empresarial, empreendedores comprometidos e capazes de transformar o país".

No Brasil, o movimento constitui-se através de uma rede entre confederação, federação e empresa júnior. São mais de 250 empresas juniores confederadas à Brasil Júnior, com mais de 7 mil universitários presentes em 14 estados.

No Rio de Janeiro existem 21 empresas juniores federadas à RioJunior, vinculadas a 10 das melhores faculdades do Estado, englobando cerca de 800 universitários de alto impacto segundo Censo coletado pela Brasil Júnior em 2013.

\section{Metodologia da pesquisa}

Trabalharemos este artigo a partir da exposição do que é uma empresa júnior, sob seus aspectos de legitimação jurídica com base no CNEJ - Conceito Nacional de Empresa Júnior. A partir disso, exporemos as instâncias que legitimam a empresa júnior em seu aspecto macro - como movimento universitário de amplitude nacional.

Para expor o movimento sob uma óptica macro, recorremos à versão 1.6 do Planejamento Estratégico em rede da Brasil Júnior, assim como ao conceito de rede utilizado como embasamento teórico para este material. No tocante da legitimação do movimento e do alinhamento da rede - articulação das empresas juniores com a federação e à confederação - mostraremos o Selo Empresa Júnior como ponto de encontro entre essas instâncias. Mostraremos, ainda, a maneira como cada empresa júnior atua nas instâncias do movimento de maneira participativa e alinhada.

A fim de identificar a congruência do planejamento da atuação do Movimento Empresa Júnior no Brasil com a sua verdadeira prática, trabalharemos as vertentes estratégicas do Movimento Empresa Júnior alinhadas a depoimentos coletados por duas grandes lideranças deste movimento: Pedro Nascimento - ex-presidente da Fluxo Consultoria, ex-presidente da RioJunior e atual vice-presidente da Brasil Júnior - e Matheus dos Santos Aguiar - ex-presidente da CEFET Jr Consultoria, ex presidente da RioJunior e ex-presidente do conselho da Brasil Junior.

Por fim, iremos expor a história da Pacto Consultoria - a Empresa Júnior de Gestão de Negócios e Turismo da UFF - contada por meio da coleta de informações de três gerações da ocupação da sua presidência: Natália Cantarino Féres (2012), Júlia Ferreira Gouveia (2013) e Hugo Pessanha Souza (2014).

\section{0 que é uma empresa júnior e questões jurídicas}

Segundo a definição presente no CNEJ - Conceito Nacional de Empresa Júnior, "As empresas juniores são constituídas pela união de alunos matriculados em cursos de graduação em instituições de ensino superior, organizados em uma associação civil com o intuito de realizar projetos e serviços que contribuam para 0 desenvolvimento do país e de formar profissionais capacitados e comprometidos com esse objetivo". 
O objetivo central das empresas juniores consiste na promoção do desenvolvimento profissional do corpo discente do Ensino Superior através da realização de projetos e serviços que favoreçam um retorno à sociedade a partir da atividade empreendedora, conforme disposição do art. $3^{\circ}$ do CNEJ.

As empresas juniores são pessoas jurídicas de direito privado, mais precisamente associações, como previsto nos termos do art. 53 e seguintes do Código Civil, devidamente registrada junto ao CNPJ/MF e devem respeitar, observar e cumprir as legislações federal, estadual e municipal.

A definição legal, em virtude da ausência de precisão técnica legistativa, ainda peca e gera dúvidas quanto ao conceito da empresas juniores. A fim de legimitar o movimento no Brasil, desde 2012 a Brasil Júnior vem trabalhando no desenvolvimento de um projeto de lei que planeja regulamentar as empresas juniores reconhecendo o seu papel como agente de transformação do nosso país. O projeto de lei PLS 437/12 atualmente tramita no senado e vem para legitimiar o trabalho que o movimento vem exercercendo desde 0 final da década de 80.

Cabe destacar que, apesar das empresas juniores serem denominadas "empresas", tal conceito não está associado àquele inerente ao Direto Comercial de "sociedade empresária" ou de "atividade empresária", mas utilizado tão somente para indicar a relação existente entre atividades desenvolvidas pelos acadêmicos e a promoção do empreendedorismo dentro das universidades.

Ainda assim, as empresas juniores podem - e devem - cobrar pelos seus serviços, para que possam arcar com seus custos. Os preços dos projetos chegam a ser até $80 \%$ mais barato do que os oferecidos por empresas seniores no mercado, e todo o excedente deve ser reinvestido no desenvolvimento da própria empresa e de seus membros.

A Brasil Júnior veda a ingerência externa nos assuntos dessas entidades na medida em que permite a participação no projeto na condição de membro associado apenas aos alunos da graduação de um determinado curso da instituição de ensino superior, nos termos do art. 7 do CNEJ.

Vale dizer que tal perspectiva de autonomia se encontra fundamentada diretamente em um dos aspectos extraídos do conteúdo jurídico do direito fundamental de associação que proíbe, em regra, a interferência estatal no funcionamento das entidades, com base no art. $5^{\circ}$, insico XVIII da CF. 35.

Por assim se constituir, todos os membros associados à empresa júnior deverão assinar termo de voluntariado, e o quadro social da empresa júnior deverá ser formado única e exclusivamente por alunos regularmente matriculados na instituição de ensino superior e no curso de graduação ao qual a empresa júnior for vinculada.

Para ser reconhecida como empresa júnior, a associação deverá estar vinculada a uma instituição de ensino superior e, pelo menos, a um curso de graduação determinado em estatuto. Será considerada empresa júnior apenas aquela cujo exercício seja reconhecido pela instituição de ensino superior à qual estiver vinculada

Para garantir que as empresas estejam de acordo com as normas definidas no CNEJ, todo ano acontece a auditoria do Selo EJ, que garante que as empresas estejam de acordo com essas conformidades.

O objetivo do Selo EJ - denominado Selo Empresa Júnior - é garantir que as empresas juniores sejam, de fato, empresas, e estejam alinhadas com o conceito nacional de empresa júnior.

\section{Instâncias: alinhamento, rede e legitimidade}

Para Hakanson apud. CÂNDIDO, ABREU (2000), "o conceito de redes interorganizacionais é abrangente: duas ou mais organizações envolvidas em relacionamentos de longo prazo, tendo como principal objetivo dinamizar os diversos processos organizacionais para o alcance da competitividade. As redes podem apresentar uma grande variedade de configurações, retratando as especificidades e os objetivos envolvidos".

Atualmente o Movimento Empresa Júnior funciona em rede no Brasil. Para garantir que o funcionamento das empresas juniores esteja alinhado ao propósito da rede, existem quatro principais instâncias que organizam este ambiente: as empresas juniores, os núcleos, as federações e a confederação. 
A federação é a representatividade estadual das empresas juniores que seguem fielmente os padrões do CNEJ e as exigências descritas no Selo Empresa Júnior. A federação tem por finalidade alinhar a força das empresas juniores dentro do seu Estado. A RioJunior é a Federação das Empresas Juniores do Estado do Rio de Janeiro e possui, em sua composição acionista, 21 empresas juniores. Cada empresa júnior federada possui cadeira jurídica na federação, que atribui aos seus representantes legais - presidentes de cada empresa júnior - influência nas estratégias de atuação do Estado.

A missão da RioJunior é representar o Movimento Empresa Júnior Fluminense e fomentar o seu desenvolvimento, através de conexões que potencializem os resultados da rede, além de fomentar novas empresas juniores dentro do estado.

A confederação é a instância de representatividade nacional das empresas juniores federadas. Cada federação possui cadeira jurídica como acionista na Brasil Júnior, a fim de possibilitar o alinhamento nacional de todos os estados que possuam federação. A Brasil Júnior tem como principal objetivo representar o Movimento Empresa Júnior e potencializá-lo como agente de formação de empreendedores capazes de transformar o país. Para isso, conta com três pilares de atuação: integração dos agentes da rede; potencialização dos resultados da rede e articulação dentro do ecossistema empreendedor.

O Selo EJ constitui uma série de documentos e exigências que comprovam a situação jurídica da empresa. Como o fato de a empresa estar vinculada à sua federação garante seu vínculo à confederação - Brasil Júnior -, caso uma empresa júnior não possua o Selo EJ, não pode ser confederada à Brasil Júnior.

Uma empresa júnior pode se federar participando do processo de federação que ocorre a nível estadual. A RioJunior - Federação das Empresas Juniores do Estado do Rio de Janeiro - organiza, por exemplo, dois Processos de Federação por ano.

Os núcleos funcionam como uma ponte entre as empresas juniores como um todo - federadas e não federadas - e a federação. Sua principal finalidade é proporcionar às empresas juniores uma maior aproximação com a federação, fomentando um networking mais forte e maior alinhamento às estratégias nacionais do Movimento Empresa Júnior.

O núcleo garante, assim, que as empresas juniores não federadas também estejam próximas à legitimidade do movimento e almejem evoluir rumo à federação. Dessa maneira, os núcleos são instâncias que funcionam como unidade dentro das universidades: reúnem empresas juniores que fazem parte de uma mesma universidade, facilitando a força da rede. No Estado do Rio de Janeiro, possuímos os núcleos da UFF, UFRJ e UFRRJ.

\section{Atuação das empresas juniores nas instâncias}

Cada empresa júnior federada é representada pelo seu presidente dentro do conselho estratégico da federação. $O$ conselho estratégico, portanto, é composto por cada um dos presidentes das empresas juniores da federação que decidem, com a facilitação do presidente do conselho, os rumos estratégicos do Movimento Empresa Júnior a nível estadual.

Já a nível nacional, o presidente do conselho e o presidente da federação atuam como conselheiros estratégicos da Brasil Júnior: deliberam as estratégias do Movimento Empresa Júnior a nível nacional. 0 conselho da Brasil Júnior é o órgão de representação máxima da confederação e delibera as decisões tomadas pela Brasil Júnior por meio da voz das lideranças de cada Estado. Fica claro, portanto, que existe uma grande articulação de rede no que diz respeito à tomada de decisão.

\section{No Brasil, o que é o Movimento Empresa Júnior hoje}

Inicialmente formadas com intuito de desenvolver as habilidades dos estudantes necessárias ao mercado de trabalho, as empresas juniores hoje constituem o maior movimento de empreendedorismo jovem no país. 
Para garantir que haja coerência dentro do movimento no Brasil, foi traçado o Planejamento em Rede da Brasil Júnior, que determina as diretrizes que o movimento deve seguir como um todo para que os resultados sejam atingidos de forma integrada.

O mapa estratégico da Brasil Junior se desdobra em objetivos que partem da missão da organização para 0 seu propósito, que é desenvolver um Brasil Empreendedor. O Mapa Estratégico do Movimento Empresa Júnior foi desdobrado em duas perspectivas estratégicas: a Formação Empreendedora e o Desenvolvimento da Rede.

O Movimento se posiciona hoje como um dos grandes agentes de transformação da educação brasileira, trabalhando em cima de três vertentes para que isso aconteça:

- A realização de serviços de qualidade - pelo desenvolvimento de projetos;

- A experiência e o aprendizado por meio da prática em gestão;

- A inserção e promoção da cultura empreendedora.

Apesar de contar com uma estrutura de processos que façam das empresas juniores instâncias empresariais, o papel da empresa júnior na formação dos jovens universitários vai além do que é definido em estatuto.

Segundo Pedro Nascimento - vice-presidente da Brasil Júnior (2014) e ex-presidente da RioJunior (2013) após quatro anos dedicados ao Movimento, hoje sua visão é bem diferente daquela que tinha quando iniciou sua trajetória como trainee da Fluxo Consultoria - Empresa Júnior de Engenharia da UFRJ:

\begin{abstract}
"Há quatro anos minha visão era bem clara: entraria na empresa júnior para melhorar meu currículo profissional, depois utilizaria tal experiência para entrar em algum estágio remunerado. (...) Acredito hoje que a capacitação profissional é importante, mas não é o fundamental da empresa júnior. A empresa júnior tem o papel fundamental de formar pessoas mais responsáveis, mais éticas, mais íntegras e, porque não, mais competentes. $A$ oportunidade de lidar com problemas, de interagir com pessoas diversas, de aplicar os conhecimentos teóricos da universidade na prática em projetos que geram impacto fazem com que o jovem, ainda numa idade de descobertas e experimentação, perceba que pode gerar impacto real e não apenas se ater a um discurso romântico ou inflamado. Creio que a empresa júnior tem o papel de formar uma geração de líderes para nosso país, não apenas um ou outro futuro executivo."
\end{abstract}

E o propósito do movimento não para por aí. Segundo Matheus dos Santos Aguiar - ex-presidente da RioJunior (2012) e ex-presidente do conselho da Brasil Júnior (2013) - o Movimento Empresa Júnior está fortemente ligado a uma atitude ousada de inovação na educação do Brasil:

\begin{abstract}
"O movimento é uma das iniciativas mais ousadas que a gente tem pra mudar a educação no Brasil. Em longo prazo, estamos contribuindo pra criar novas formas de educação pro Brasil - e não só de educação, mas também de inspiração pros jovens de hoje, de conseguir captar e "tangilbilizar" um pouco do sonho dos jovens de hoje e do sonho que a gente tem pro Brasil. Durante muito tempo a gente falou que o Brasil era o país do futuro, durante muito tempo a gente esperou que alguém construísse esse Brasil e hoje, por meio dessa geração de jovens que a gente tem, a gente sabe da responsabilidade de que quem tem que construir o Brasil somos nós - é aí que entra a questão do espírito empreendedor: é isso que faz a diferença na hora de formar uma geração que pode mudar o país."
\end{abstract}

\title{
Pioneirismo, queda e reestruturação: Pacto Consultoria
}

A Pacto Consultoria é a Empresa Júnior de Gestão de Negócios e Turismo da Universidade Federal Fluminense. Foi fundada em outubro de 1995 por estudantes do curso de Administração e, posteriormente, incluiu em seu organograma os cursos de Ciências Contábeis, Ciências Atuariais e Turismo.

A Pacto Consultoria foi uma das empresas juniores fundadoras da RioJunior - a Federação das Empresas Juniores do Estado do Rio de Janeiro. Participou ativamente do seu fomento e do início do seu trabalho na articulação do movimento a nível estadual. 
Porém, em 2005, a federação planejou organizar o maior encontro de empresários juniores da história do país. Este evento trouxe à federação uma dívida surpreendentemente grande e, como as empresas juniores são acionistas da federação, cada uma delas precisou assumir um percentual desta dívida. Na época, a Pacto não possuía reserva financeira suficiente para cobrir esta despesa e, consequentemente, precisou sair da federação em decorrência da sua quebra financeira.

Alguns anos se passaram e a empresa, mantida fora da federação, passou por alguns altos e baixos até 0 ano de 2012. Neste ano, a gestão da Pacto Consultoria foi ocupada por uma equipe muito motivada - após a confirmação de um indicativo de greve houve uma grande redução no número de consultores, mas eram consultores movidos pela paixão. Esta gestão centralizou o seu foco na reestruturação da gestão interna, preparando a empresa para a chegada dos estudantes que ingressariam no pós-greve.

Durante o ano de 2013, a empresa iniciou uma gestão mais focada na participação da rede. Percebendo que já havia buscado uma estrutura suficiente para voltar a atuar, notou que já estava pronta a retornar à federação. A Pacto reestruturou o seu processo seletivo interno e captamos membros muito alinhados às competências necessárias para a realização efetiva dos nossos direcionadores estratégicos.

Assim, a Pacto voltou à RioJunior. Em dezembro de 2013 recuperou a sua cadeira jurídica na participação ativa das políticas do Movimento Empresa Junior no Estado do Rio de Janeiro.

Hoje, em 2014, a Pacto é vista pelo Movimento Empresa Júnior fluminense como uma empresa júnior referência em inovação, determinação, representatividade e excelência em gestão de pessoas. A Pacto é reconhecida por possuir uma cultura organizacional claramente evidenciada pela paixão dos seus consultores e pelas suas estratégias de participação na rede. Atualmente, $37 \%$ dos membros da Pacto Consultoria ocupam cargos externos distribuídos pela RioJunior, pelo UFF Júnior - Núcleo das Empresas Juniores da UFF - e pela equipe organizadora do EFEJ - Encontro Fluminense de Empresários Juniores.

\section{Considerações finais}

Hoje em dia o Movimento Empresa Júnior encontra três desafios de base a serem superados: garantir a legitimação como empresa, ganhar força expansionista nas regiões do interior do estado e quebrar a configuração elitista dos universitários que compõem este movimento.

No que diz respeito ao desafio de garantir a legitimação das empresas juniores como empresas autênticas: 0 projeto de lei PLS 437/12 tem sido o veículo de resolução para este desafio. Com a efetividade deste projeto de lei as empresas juniores ganharão mais força de mercado no reconhecimento de sua atividade e atuação empresarial.

O Movimento Empresa Júnior, hoje, possui grande força nas regiões metropolitanas do Estado do Rio de Janeiro. As regiões mais afastadas deste centro, entretanto, ainda não possuem uma grande representatividade de empresas juniores federadas. Um dos grandes desafios de expansão da federação, hoje, é justamente levar a estas regiões mais afastadas suporte para o fomento do movimento nas universidades.

O MEJ traz à sociedade um dilema que, sem dúvida alguma, terá sua resolução como um grande desafio: 0 Movimento Empresa Júnior, por ser um movimento sem fins lucrativos, impossibilita que seus alunos consultores recebam salário para realizarem as suas atividades. Estes consultores podem e devem, pela proposta do movimento, receber reembolsos destinados a despesas oriundas da realização de projetos para clientes (como transporte, alimentação, etc). Entretanto, essa questão da remuneração coloca o movimento como refém de uma questão social: os jovens que se mantem muito tempo no movimento são aqueles que possuem condições financeiras para que possam, por algum tempo, permanecer em atividades voluntárias pelo auxílio dos pais. Este ponto, portanto, tem caracterizado o movimento como um palco parcialmente elitista. 0 desafio das empresas será, portanto, se empenhar para oferecer ao mínimo os reembolsos necessários para a atuação dos seus membros. 
O MEJ é, sem dúvidas, um movimento que está ganhando forças na formação de uma geração de jovens empreendedores com propósito de transformarem o Brasil. A Pacto Consultoria está contida nesta rede de empresas juniores, protagonizando no meio acadêmico da Universidade Federal Fluminense como agente de transformação no seu ecossistema empreendedor.

\section{Referências:}

BRASIL JÚNIOR. Acontece no MEJ: Projeto de Lei é aprovado na CE do Senado, Out 2013. Disponível em: <http://www.brasiljunior.org.br/noticias/mostrar/532>. Acesso em: 10 de abril de 2014.

BRASIL JÚNIOR. CNEJ: Conceito Nacional de Empresas Juniores, Jun 2012.

Disponível em: <http://www.brasiljunior.org.br/arquivos> Acesso em: 05 de abril de 2014.

DIDIER JR., Fredie; MARQUES, Alessandro. (Coord.) Empresa Júnior: Aspectos Jurídicos, Políticos e Sociais. Salvador: Juspodivm, 2013, 232 p. 